Science for Education Today

2019, том 9, № 3

http://sciforedu.ru

ISSN 2658-6762

(С) А. Р. Садыкова, И. В. Левченко, Н. А. Усова, Ю. Б. Икренникова,

А. В. Коржуев, Е. Л. Рязанова

DOI: $10.15293 / 2658-6762.1903 .05$

УДК 167.17

Эксплицирование логико-гносеологической атрибутики из педагогического текста как фактор, влияющий на методологическую грамотность педагога-исследователя

\author{
А. Р. Садыкова, И. В. Левченко, Н. А. Усова, Ю. Б. Икренникова, \\ А. В. Коржуев, Е. Л. Рязанова (Москва, Россия)
}

Проблема и цель. Авторами исследуется проблема логико-гносеологического контента педагогического знания и методов его нахождения. Цель статьи - выявление того, как влияет освоение умения эксплицирования логико-гносеологической атрибутики из текста на методологическую грамотность педагога-исследователя.

* Исследование выполнено при поддержке Министерства образования и науки РФ по Проекту «Повышение конкурентоспособности ведущих российских университетов среди ведущих мировых научно-образовательных центров (5-100)»

Садыкова Альбина Рифовна - доктор педагогических наук, профессор кафедры информатики и прикладной математики, Институт цифрового образования, Московский городской педагогический университет.

E-mail: albsad2008@yandex.ru

Левченко Ирина Витальевна - доктор педагогических наук, профессор кафедры информатики и прикладной математики, Институт цифрового образования, Московский городской педагогический университет.

E-mail: ira-lev@yandex.ru

Усова Наталья Александровна - кандидат педагогических наук, доцент кафедры информатики и прикладной математики, Институт цифрового образования, Московский городской педагогический университет.

E-mail: usova-n@mail.ru

Икренникова Юлия Борисовна - кандидат педагогических наук, доцент кафедры педагогики и психологии профессионального образования, Московский государственный университет технологий и управления им. К. Г. Разумовского (ПКУ).

E-mail: ikren@yandex.ru

Коржуев Андрей Вячеславович - доктор педагогических наук, профессор кафедры медицинской и биологической физики, Первый Московский государственный медицинский университет им. И. М. Сеченова.

E-mail: akorjuev@mail.ru

Рязанова Елена Леонтьевна - кандидат педагогических наук, доцент кафедры медицинской и биологической физики, Первый Московский государственный медицинский университет им.

И. М. Сеченова.

E-mail: scarobey64@mail.ru 
Методология. В прочессе исследования использован комплекс методов, включающий: а) анализ научной литературы по теме статьи, рефлексию содержания педагогического знания и научно-педагогических методов исследования с выявлением актуального не исследованного сегмента педагогической теории; б) выдвижение в качестве гипотезы предположения о влиянии освоения педагогом-исследователем умений экспликации логико-гносеологической атрибутики из научного текста на уровень его методологической грамотности; в) теоретический компонентный анализ причинной обусловленности повышения уровня методологической грамотности педагога-исследователя; г) локальный педагогический эксперимент, подтверждаюичий правомерность гипотезы.

Результаты. Выявлено, что деятельность педагога-исследователя, связанная с распознаванием и логико-содержательным продолжением обучаюшимся аспирантом находимых в анализируемых текстах эмпирических выводов, теоретических обоснований, сравнений, сущностного анализа феноменологических проявлений, результатов анализа факторов, оказывающих влияние на характер протекания изучаемого прочесса, способствует повышению уровня методологической грамотности исследователя в области образования. Это выражается в способности грамотно дефинитивно кодировать педагогическое поле, осуществлять его классифицирование, соблюдать при формулировке выводов законы достаточного основания, тождества, противоречия, исключенного третьего.

Заключение. Методологическая грамотность педагога-исследователя причинно детерминирована (на уровне одной из значимых причин) умением эксплицирования логико-гносеологического контента из анализируемого научного текста: а) определения достаточности, содержательной и логической корректности, правильной адресуемости к рассматриваемым феноменам теоретических и эмпирических обоснований; б) корректного анализа влияюших на феномены педагогики факторов; в) проецирования исследовательского рассмотрения в сущностный формат.

Ключевые слова: логико-гносеологический контент педагогики; эксплицирование смыслов в тексте; обоснование эмпирическое; обоснование теоретическое; обоснование контекстуальное; логическое опровержение выводов; корректная педагогическая аналитика.

\section{Проблема исследования}

В современной философии науки считается, что источником истины не может быть отдельный исследователь или методолог - это право присваивается только научному сообществу. В связи с этим возникает необходимость полиформатного научного диалога между субъектами этого сообщества, в процессе которого осуществляется научная коммуникация, и главным в этом процессе, с нашей точки зрения, является возможность участников задать друг другу вопрос: на чём основано ваше умозаключение, чем вы можете аргументировать свой вывод, из каких посылок вытекает ваша уверенность в декларируемом выводе. На научном языке этот контент именуется логико-гносеологическим кодом гуманитарного познания, к которому педагогическое исследование с полным правом может быть отнесено. Этот вывод подтверждается анализом содержания исследований отечественных и зарубежных авторов, результаты которых представлены во множестве работ [1-4].

Одним из способов диалога в педагогическом сообществе является заочный диалог исследователя с автором читаемого текста, и в этом случае возникает проблема адекватного эксплицирования и распознавания логико-гносеологического контента из содержания анализируемого текста, выявления читателем того, как автор статьи, диссертации, моногра- 
фии и т. п. позиционирует свои выводы, умозаключения, предположения, аргументы для их подтверждения или какие использует основания для опровержения выводов своих оппонентов. Как показывает достаточно длительный опыт обучения магистрантов и аспирантов педагогических специальностей, такие умения сформированы у начинающих педагогов-исследователей весьма слабо. Это крайне затрудняет процесс педагогического исследования практически на всех его стадиях - от нахождения актуального для начала исследования проблемно-содержательного поля, формулировки проблемы и гипотезы до осознания степени подтверждаемости выдвинутой гипотезы экспериментом. Это затрудняет и процесс научного руководства и экспертирования научных квалификационных работ.

Экспликация логико-гносеологического контента из читаемого текста есть сложносоставная деятельность рефлексивного характера, к которой относятся умения педагога-исследователя, анализирующего предъявленный каким-либо автором текст, сегментировать его на такие отрывки, которые соответствуют содержательно законченному акту эмпирического или теоретического обоснования предъявленного вывода, его соотнесению с аналогиями, экстраполяциями, индуктивными обобщениями, дедуктивными выведениями следствий исходных положений. Деятельность исследователя, работающего с педагогическим текстом, включает ряд компонентов: а) умение обозначить конкретный фрагмент логикогносеологической атрибутики в читаемом тексте или способность выявить его отсутствие (когда автор выражает свою интенцию бездоказательно); б) умение понять то, как автор

\footnotetext{
${ }^{1}$ Shelley H. Billig, Alan S. Waterman. Studying ServiceLearning: Innovations in Education Research Methodology. - Routledge, 2014, 276 p.
}

осуществляет то или иное теоретическое, эмпирическое или контекстуальное обоснование (аргумент к традиции, здравому смыслу, вере, авторитету), как использует аналогию, обобщение, экстраполяцию, выявить корректность такой процедуры; в) умение сконструировать в ответ на читаемую несообразность собственную критическую «добротно» обоснованную устную или выраженную научным письменным языком форму [5].

Сегодня в некоторых отечественных и зарубежных исследованиях можно обнаружить целый спектр мнений об отнесении педагогического знания к области Arts and Humanities («высокого искусства»), и невозможности представить его в научно-теоретической форме [6]. Такие выводы подробно представлены в работах по отечественной и зарубежной философии, методологии науки, педагогического науковедения: на трудности логико-гносеологического кодирования наук об образовании указывает Wolfgang Brezinka [7], на трудности корректного научного выстраивания инновационных образовательных проектов указывает Shelley H. Billig ${ }^{1}$, ряд противоречий в процессе конструирования методологии социогуманитарного и психолого-педагогического научного познания анализирует в своей статье Tirhekar Sushma Shirish²; тезис о несовместимости опыта, который человек приобретает в процессе учения, с методологическим представлением процесса обучения выдвигает D. Lundie [8]. Однако анализ других научных источников подтвердил наш вывод о том, что даже в социогуманитарной науке «слабой гносеологической версии» должна быть представлена та или иная теоретическая форма: G. Gardiner ${ }^{3}$ пытается ввести

\footnotetext{
${ }^{2}$ Shirish T. S. Research Methodology in Education. Lulu Publication, USA. - 2013. - 122 p.

${ }^{3}$ Gardiner G. Teleologies and the Methodology of Epistemology // Epistemic Evaluation: Purposeful Epistemology
} 
в теоретический сегмент эдукологии категорию причинно-целевого обоснования [9]; D. Pritchard обосновывает попытки введения в эпистемический круг наук об образовании такие формы, как гипотеза и методы её теоретического и экспериментального подтверждения/опровержения [10]. Уже сегодня ряд традиционно выделяемых в науковедении логико-гносеологических компонентов в педагогическом знании и процессе его получения так или иначе проявлены: идею логико-содержательной выверенности теории образования как части научного мировоззрения обсуждает J. Shepperd [11]; эскиз структуры образовательной теории и её исследовательский потенциал выявляет T. Lesz [12]; синтез общенаучной методологии и психологии с педагогикой, основные подходы к построению наук о личности и её образовании выдвигает в своих исследованиях J. Wettersten [13]. На необходимость поиска возможности представить педагогику и эдукологию в теоретическом формате, ориентированном на основы логики и гносеологии, явно указывает в своих книгах и статьях А. Kornienko [14], формулируя свою идею в терминах «концепции общества знаний»; корректный междисциплинарный формат исследований в области образования обосновывают B. Barczynski и R. Kalina [2], научно выверенный трансдисциплинарный формат эдукологии и психологии предлагают В. Mallaband и C. Wood [15]. Множество более конкретных идей данного направления, вплотную подводящих тему методологизации педагогики к отображению в ней таких логико-гносеологических атрибутов, как проблемный формат, гипотеза, концептуальная и нормативная модели, представлено в работе J. Koskinen [16]; на необходимость осмысления методологами педагогики проблемы соотнесения объективной педагогической реальности и предметно-научной реальности указывает М. Б. Сапунов [17]; естественно-научный аналог такого соотнесения представляет В. В. Зуев [18]; один из вариантов теоретического форматирования степени содержательной наполненности различных сегментов научного поля педагогики рассмотрен в статьях [19; 20].

Среди не исследованных проблем данного поля мы считаем возможным обозначить контент, объединяющий логику и гносеологию педагогического знания и методов его получения, - это клишированный выше логикогносеологический код педагогики. В качестве публикаций, подтверждающих обозначаемую нами актуальность темы статьи, мы могли бы использовать и научный диалог авторов N. Snaza и H. Letiche [21; 22]. Сами названия статьи автора [21], провозглашающего науковедческую педагогическую тему и подход к её раскрытию, и ответной - его оппонента по диалогу [22], свидетельствуют о неблагополучном положении в конструировании «научного портрета» педагогики: они переводятся на русский язык как «озадачивающая педагогика» (первое прилагательное допускает также перевод с помощью клише «трудно понимаемая...», «запутанная...», «изумляющая педагогика») у H. Letiche, и как «научно скомпрометированная...», «насыщенная массой случайностей педагогика» у N. Snaza. Недостаточная выявленность научного статуса педагогики подтверждается и содержанием работ двух полемистов: с одной стороны, подчёркивается специфичность объекта педагогического исследования, его резкое отличие от объектов естественных наук и невозможность конструирования педагогической теории на «классической» (естественно-математиче-

/ (Eds) Henderson D. K., Greco J. - Oxford University Press, 2015. - P. 31-45. DOI: https://doi.org/10.1093/acprof:0so/9780199642632.003.0002 
ской) модельной основе; с другой - отмечается острая необходимость теоретического обобщения, систематизирования огромного массива накопленных практическим образованием опытных данных, идей, подходов, концепций, теоретических построений и т. п. Всё это в полной мере относимо и к текстам педагогических исследований: «запутанная, удивляющая своей невыстроенностью педагогика» [21; 22] продуцирует такие же публицистические, пересыщенные метафорами, трудно воспринимаемые читателями тексты.

Не имея на сегодня содержательно законченного вывода о способах решения всего множества отмеченных выше проблем, мы тем не менее можем гипотетично обозначить в качестве средства теоретического нормирования педагогики вычленение её логико-гносеологической атрибутики, эксплицируемой исследователями из читаемых научных текстов. Научная проблема статьи адресуется к выявлению того, каким конкретно образом включённое чтение научных текстов по педагогике, направленное на выявление логико-гносеологического контента знания об образовательной реальности, влияет на методологическую грамотность педагога-исследователя. Целью статьи является выявление причинной обусловленности методологической грамотности педагогаисследователя освоением умения экспликации логико-гносеологической атрибутики из научного текста педагогического поля.

\section{Методология исследования}

В процессе исследования мы использовали комплекс методов, включающих: а) анализ научной литературы по теме статьи, ориентированной на источники философские, методологические и науковедческие, включающие классику философии науки и современное её видение; б) выявление недостаточно разработанных сегментов логико-теоретической формы в педагогике и методологии её исследования; в) рефлексию логико-гносеологической атрибутики текстового содержания современного педагогического знания, форм её представления научнопрактическому социуму; г) выдвижение гипотезы о том, что освоение умений эксплицирования логико-гносеологического контента из научных текстов способствует повышению методологической грамотности исследователя; д) теоретический анализ, направленный на осмысление причинной детерминированности методологической грамотности исследователяпедагога умением находить и интерпретировать логико-гносеологические компоненты в научном тексте; е) выявление конкретных компонентов логико-гносеологического контента текстового педагогического знания и тех методологических умений, сформированность которых они обусловливают; ж) локальный педагогический эксперимент, проявляющий степень влияния углублённого логико-гносеологического анализа педагогического текста на методологическую грамотность обучающихся магистрантов и аспирантов педагогического профиля.

\section{Результаты исследования}

Приведём теперь обоснование вывода, доказывающего влияние обучения аспирантов экспликации логико-гносеологической атрибутики из педагогического текста на уровень их методологической грамотности. Адресация темы нашего исследования к педагогическому тексту естественным образом опосредует логико-гносеологическое рассмотрение процесса чтения такого текста и последующего его корректного «аналитического заимствования» педагогом-исследователем в собственном текcme. Проводя аналитическую работу на различных этапах своего исследования, его автор задействует самого разного профиля и содержа- 
ния тексты педагогических, философских, методологических и других работ предшественников, составляет аналитические обзоры, справочные отчёты, конструирует аналитические фрагменты собственных исследовательских текстов. К числу простейших форм отражения логикогносеологической атрибутики в тексте аналитического характера, читаемом педагогом-исследователем, относится, например, такая: «автор в анализируемом тексте утверждает..., автор анализирует...», «на основе обследования ... (такой-то выборки) автор делает вывод о ...» К более нестандартным сюжетам относятся, в частности такие: a) «автор читаемого текста, конечно, не мог не знать... (о таких-то результатах, подходах, идеях, концепциях), однако этот контент в своих рассуждениях не учитывает»; б) «цитируемый автор утверждает, что ..., но это утверждение вряд ли можно считать верным»; в) «вряд ли можно считать правильным мнение о том ...»; г) «существует исключительно ложная традиция приписывать ... (такому-то автору) исключительно идеи, связанные с личностно-ориентированным образованием»; д) «читаемый автор мог бы возразить моему мнению, но в других источниках сохранились воспоминания о том, что с ним согласны ... (такие-то учёные)»- в этом случае предполагается, что читающий текст аналитик знает работы читаемого автора, выходящие за рамки одного указанного выше сегмента педагогики; е) «стремясь писать только о том, что ему известно из достоверных документов, автор...»

Эти шесть примеров аналитических умозаключений, отражённых в читаемом тексте, по большей части относятся к обсуждённому выше опровержению эмпирическому, - при этом, конечно, выделенные фрагменты в тексте продолжаются. Первый из обозначенных выше сюжетов должен быть целесообразно продолжен читающим текст исследователем, например, так: в не использованных для анализа публикациях автор мог бы найти идеи, существенно дополняющие его аналитическое видение проблемы..., а также идеи, суть которых противоположна тем, которые он использовал. Второй текстовый сюжет целесообразно дополняем тем, почему вывод читаемого автора фальсифицируется - для эмпирического контента это может быть адресация к эмпирическим данным, укрывшимся от внимания читаемого автора, которые свидетельствуют о чём-то противоположном, например: автор обосновывает широко распространённый тезис об избыточности высшего образования в РФ, однако в источнике ... (таком-то) приведены обоснованные на репрезентативной статистической базе данные о том, что это миф, и охваченность высшим образованием в РФ ниже, чем в западных странах и примерно соответствует показателям стран бывшего социалистического лагеря. Более детальный аспирантский анализ (продвинутый уровень) должен продолжить прочитанную эмпирику в исследование того, как исследуемая «охваченность» коррелирует с потребностями рынка труда в различных странах. Аналогичны и понятны по содержанию и модификации читателя текстов всех следующих типов (г, д, е) - это только что проиллюстрированные эмпирические опровержения.

Продолжая раскрытие логико-гносеологического контента, эксплицируемого педагогомисследователем из читаемого текста, отметим, что эмпирическое опровержение сочетаемо с теоретическим, и это иллюстрируется в таких задействуемых начинающими педагогами-аналитиками текстовых фрагментах: а) «конечно, не следует чрезмерно сближать теории развивающего обучения В. В. Давыдова и Л. В. Занкова, как это делает в обзоре литературы цитируемый исследователь, но сама связь между ними (отражённая, в частности в одинаковых их названиях) не может быть случайной»; б) «у автора, 
как у многих его предшественников, давно сложилось мнение, что решающее значение в усвоении учебного материала имеет не степень осмысления студентами его научной значимости, а логическая структура, отображающая его в учебниках и пособиях, однако (!) едва ли не стоит учитывать сложную палитру связей между этими двумя факторами».

Анализирующий приведённые выше фрагменты текстов обучающийся аспирант, осознав, что приведённые умозаключения синтезируют эмпирические обоснования с теоретическими, при поддержке педагога мотивируется к продолжению прочитанных выводов (конечно, в зависимости от того, как представил это сам читаемый автор) - в примере первом обучающийся аспирант приходит к выводу о $c y$ щеественной степени сходства двух подходов к методическому проекту развивающего обучения, выраженной в том, что оба обсуждаемых подхода идею развития связывали с ранним включением школьника в деятельность теоретического и рефлексивного характера, с конструируемым под руководством учителя теоретически содержательным обобщениям. Различия двух подходов были адресованы к методической конкретике замысла. В примере втором мысль автора читаемого текста могла бы быть продолжена самостоятельным нахождением аспирантом-педагогом связи между научной значимостью учебного материала и его логической просвеченностью для студента - одной из таких связей могла бы быть та, которая выражена формулой «одно как часть другого»: та или иная красивая логическая форма относима к научной ценности открытия и, следовательно, отображающего это открытие учебного материала.

Заявленный в начале данного раздела статьи контент включает и то, что именуется в логике сравнением - например, это иллюстрируемо таким примером: «В анализируемом тексте приводятся мнения двух известных педагогов, - кто же из них прав? Сама такая постановка вопроса безнадёжно упрощает суть дела. Из исторической ретроспективы можно ясно увидеть, что и то, и другое были абсолютно необходимы в отечественном образовании, сыграв ... (такую-то важную роль)». Прочитавший такой текст обучающийся аспирант мотивируется педагогом к содержательному продолжению предъявленного вывода, так или иначе приводящего его к осознанию неправомерности оценки предлагаемого спора авторитетов в логике «кто же прав?» Например, если в предлагаемом для анализа тексте сюжет выстроен вокруг критики идеи информатизации школьного образования во второй половине 1980-х гг. (кто был прав: те, кто доказывал необходимость обучать школьников программированию (1), или те, кто ратовал за формирование умений пользовательского характера, анализа информационных баз, пользования пакетами прикладных программ (2)?), то вывод в стиле «и то, и другое было необходимо» вполне понятен.

Имеет смысл привести примеры отображения в используемых при обучении аспирантов текстах педагогической аналитики такого логико-гносеологического конструкта, как анализ факторов, влияющих на характер протекания исследуемого явления, сравнение степени ux влияния: «Было бы вместе с тем неправомерно полагать ..., однако было бы неправомерным и игнорировать ... (нечто противоположное или одновременно с обозначенным ранее фактором существующее в образовании), преуменьшать возникающие в практике обучения трудности». Или такие два аналогичных варианта аналитического текста: а) «нет сомнения, что ..., но, и нельзя упускать из виду такое обстоятельство...»; б) «читая текст, в котором обсуждается различие между проблемным и исследовательским обучением, нельзя не обратить внимания на существенное их родство». В науках «сильной гносеологической версии» 
анализ факторов неизбежно сопровождается выбором количественного соотношения, позволяющего оценить факторы значимые и пренебрежимые - в педагогике в большинстве случаев такой возможности нет. В приведённых примерах число таких факторов равно двум, но по сравнению с предыдущими рассмотренными выше случаями здесь есть гораздо большая возможность для анализирующего текст аспиранта представить свои возражения его автору. В первом примере, приведённом в данной части статьи, обучающийся аспирант-читатель может возразить автору: ваш первый, противоположный по направленности влияния второму, фактор не столь значим, как обозначенный первый. Например, ратуя за «ураганное» наполнение учебного контента цифровыми электронными средствами, обозначая это как тренд современного образования во всём мире, вы забываете о том, что чрезмерное и педагогически (и психологически) не концептуализированное расширение цифрового контента обучения невольно способствует потере студентами и школьниками умений внимательно осознавать смысл учебного материала, фрагментируют процесс его восприятия, о чём подробно написано в книге современного немецкого исследователя М. Шпитцера «Антимозг. Цифровые технологии и мозг».

Теперь приведём текстовые иллюстрации такого несколько раз обсуждённого выше логико-гносеологического атрибута как сущзностныий формат педагогического анализа, выявление иллюзорных эффектов, мифологем, традициионных заблуждений: а) «если кратко сформулировать суть мысли читаемого произведения, ...»; б) «нередко в нём видели непримиримого противника ... (такого-то подхода, взгляда, идеи), однако анализ прочитанного свидетельствует как минимум о неоднозначной оценке»; в) «было бы непростительной ошибкой на основе этих рассуждений прийти к выводу о том, что...»; г) «не следует ли на основе читаемого прийти к выводу о том, что ...? Мы считаем, что нет, и для этого есть несколько серьёзных доводов»; д) «эти строки читаемого текста можно было бы расценить как выражение прекраснодушной утопии..., если бы...»; д) «нередко эту мифологему истолковывали так, что ..., между тем, если подробно разобраться, то выявляется...»; е) «автор восхищается результатами внедрения в практику образования ... (такой-то инновации) и внешне действительно всё обстоит самым лучшим образом, однако, ...»; ж) «тот факт, что читаемый автор рассматривает ... (такой-то педагогический факт) исключительно как ущербность, очень огорчает, поскольку...»; 3) «приведённое автором текста столь сложное и стилистически громоздкое определение тем не менее в данном случае вполне уместно, поскольку... (его краткий вариант не отразил бы всей палитры смыслов определяемого феномена образования)»; и) «как это ни покажется удивительным, результаты исследования эффективности изобретённой автором методики показывают, что наряду с неоспоримым позитивом она проявляет и ряд побочных эффектов»; к) «конечно, то, что описывает автор в ключе негативном, есть чрезмерно радикальная и одностороння образовательная программа, но (!) нельзя не признать, что на определённом этапе развития образования без неё нельзя было обойтись. Всё дело в том... (следует тот или иное содержательное подкрепление)».

Здесь возможность для обучающегося аспиранта критически проявить себя на научном поприще кратно выше, чем в предыдущих случаях - палитра логико-содержательных сюжетов мышления очень широка и однозначно методически не кодируема.

В процессе исследования мы пытались понять то, как процесс выявления педагогом-ис- 
следователем всей описанной выше логико-гносеологической атрибутики (эмпирическое и теоретическое подтверждение выводов, сравнение, анализ факторов, влияющих на тот или иной педагогический феномен, сущностный формат педагогического анализа) способствует повышению уровня методологической грамотности исследователя. Последнюю мы считаем возможным отобразить как совокупность грамотно осуществляемых исследователем-педагогом умений: а) формулировки корректных педагогических определений, проецирующих исследуемое качество личности, тот или иной педагогический подход в выбранную теоретическую сетку, позволяющих в раскрывающей части представить совокупность признаков, просвеченную с точки зрения критерия полноты; б) опосредуемого предыдущим умения корректного разделения изучаемой совокупности, её классификационного представления, выверенного с точки зрения «области покрытия» классификационными компонентами исследуемого педагогического поля, их непересекаемости; в) умения соблюдать в процессе выдвижения выводов базовых законов логики (закона тождества, противоречия, достаточного основания, исключённого третьего).

Описанный выше экспликационный логико-гносеологический контент текста в качестве инструментария повышения методологической грамотности педагога-исследователя отображался нами в образовательном процессе МГУТУ им. К. Г. Разумовского по программам аспирантуры и магистратуры педагогического профиля. В качестве диагностического инструментария для оценки эффективности влияния умения эксплицировать и интерпретировать логико-гносеологический контент текста на методологическую грамотность исследователя мы использовали результаты выполнения аспирантами контрольных заданий. Уровень правильных ответов на достаточно простые задания, связанные с аналогичными приведённым в тексте статьи эмпирическими подтверждениями и опровержениями, повысился от начального этапа обучения до финального не очень значительно: до начала экспериментального обучения адекватный ожидаемому педагогами-экспериментаторами ответ по поводу корректного продолжения эмпирического опровержения читателя авторского утверждения представили 58 \% аспирантов, по его окончании - 76 \% в 2016/17 учебном году, в 2017/18 году эти показатели соответственно равнялись $65 \%$ и $78 \%$. Это объяснялось достаточно простым контентом, усваиваемым аспирантами интуитивно, на базе предшествующего вузовского обучения. Более интересен анализ ответов аспирантов на нетривиальные вопросы и достаточно сложные задания, в которых составителями специально совмещались несколько логических и содержательных несообразностей - их предлагалось выявить обучающимся, прошедшим годовой цикл обучения. Первым вопросом был такой: в одном источнике автор предлагает тему «Что такое игра: мышление или деятельность?» и приводит вывод о том, что игра - не деятельность, $a$ деятельностная форма высшей психической деятельности. Выявите и обоснуйте все допущенные автором логические и содержательные несообразности. Аспиранты, выполнявшие данное задание до начала обучения, в большинстве своём затруднились дать вразумительные ответы, указав лишь на трудность её понимания. Лишь $12 \%$ аспирантов привели в своих ответах утверждения о том, что исходный вопрос, требующий отождествить игру с одним из двух психологических атрибутов (мышление - деятельность), некорректен, так как заранее очевидно, что такое отождествление не может никогда быть справедливым. 5 \% участников эксперимента указали на стилистическую избыточ- 
ность фразы (три раза повторилось слово «деятельность»). Других ответов не было обнаружено.

Среди ответов аспирантов, освоивших экспликацию и интерпретацию логико-гносеологической атрибутики научного текста, также были представлены два отмеченных выше ответа, но вдобавок к данным двум множество таких, которые свидетельствовали о повышении уровня методологической грамотности: 64 \% участников вдобавок к невозможности отождествления игры и одного из двух атрибутов психики указали на двоякую возможность трактовки клише «игра - мышление или деятельность»: первая, как уже было указано, принципиально неверна; вторая «прощает» автору стилистическую некорректность и перефразирует вопрос «игра относится к области мышления или к области деятельности?» Однако дальнейшее продолжение рассуждений «за автора» осуществить обсуждаемые участники эксперимента затруднились. 38 \% обучавшихся аспирантов продолжили авторское рассуждение и пришли к выводу о том, что исходный посыл пытается свести игру к одному из двух содержательных полей психологии, при этом очевидно даже при слабом знании психологии, что эти поля пересекаются, по крайней мере, потому что мышление есть деятельность, - на этой основе участники эксперимента вывели такой тип логического нарушения читаемого автора, как некорректное разделение целого на части. 45 \% участников данного этапа эксперимента в своих ответах обратили внимание на авторское клише «...деятельностная форма высшей психической деятельности»- соединив в своей критике нарушения содержательные (деятельностная форма ... деятельности, - выражение, по меньшей мере, странное, - вряд ли можно предположить, что существует бездеятельностная форма деятельности!) и логические, связав последние с неверным соотнесением целостного образования и ракурса его рассмотрения. Позитивные приращения в умениях, относимых к методологической грамотности, проявились и при анализе других ответов на диагностические вопросы похожего содержания и, по нашему мнению, могут считаться на базе исследованной выборки обоснованными.

В процессе эксперимента мы стремились обнаружить степень влияния усвоения экспликации логико-гносеологического контента из педагогического текста на уровень общеметодологической подготовки аспирантов и другими способами. В частности, мы выявляли это влияние посредством заданий на выявление корректности предлагаемых составителями определений. Приведём результат выполнения более сложного задания, связанного с анализом определения воспитания, предложенного А. М. Новиковым: воспитание - развитие направленности личности, которая рассматривается как совокупность устойчивых мотивов, ориентирующих деятельность личности; её формами являются: влечения, интересы, склонности, идеаль, мировоззрение, порывы, убеждения, ценности, ценностные ориентации. В качестве аналитического отклика магистрантов и аспирантов мы ожидали выявления того, что сведение воспитания только к направленности личности и её раскрытие как совокупности устойчивых мотивов неправомерно (в правой, раскрывающей части определения нет полноты отражения всех признаков раскрываемого феномена), приведённое искусственное усечение не учло того, что устойчивый мотив не исчерпывает воспитания, оно должно с необходимостью быть добавлено формированием у воспитанника умения выстраивать программу собственных действий по реализации этого мотива, осуществлять эти действия и осмысливать их результат. Полностью результат диагностики представлен в таблице 1. 
Результат выполнения диагностического задания на выявление корректности определения (метод поэлементного анализа). Общее число участников 132 человек (2017/18 уч. г., МГУТУ им. К. Г. Разумовского)

The result of the diagnostic task to determine the correctness of the definition (element-by-element analysis method). The total number of participants 132 people (2017/18, Moscow State Technical University named after K. G. Razumovsky)

\begin{tabular}{|c|c|c|}
\hline $\begin{array}{c}\text { Элементы методологического знания, отображённые в } \\
\text { ответах участников эксперимента }\end{array}$ & $\begin{array}{c}\text { Число участников, } \\
\text { представивших дан- } \\
\text { ный элемент знания в } \\
\text { контрольной группе (в } \\
\text { процентах от общего } \\
\text { числа участников) }\end{array}$ & $\begin{array}{c}\text { Число участников, } \\
\text { представивших данный } \\
\text { элемент знания в экспе- } \\
\text { риментальной группе } \\
\text { (в процентах от общего } \\
\text { числа участников) }\end{array}$ \\
\hline $\begin{array}{l}\text { 1. Отразили то, что в раскрывающей части определения } \\
\text { не отображена полнота раскрываемой совокупности } \\
\text { признаков }\end{array}$ & 11 & 34 \\
\hline $\begin{array}{l}\text { 2. К ответу п. } 1 \text { добавили существенную степень пересе- } \\
\text { чения признаков в раскрывающей части определения, } \\
\text { указав, что включённое туда мировоззрение включает } \\
\text { неправомерно поставленные с ним в один ряд идеалы, } \\
\text { убеждения и ценности }\end{array}$ & 8 & 56 \\
\hline $\begin{array}{l}\text { 3. Указали, что при определении воспитания допущена } \\
\text { содержательная некорректность: не отображена пози- } \\
\text { тивная направленность всех раскрывающих воспитание } \\
\text { компонентов }\end{array}$ & 20 & 76 \\
\hline 4. Представили в ответах все четыре $($ п. $1,2,3)$ позиции & 0 & 25 \\
\hline
\end{tabular}

Результаты, показанные в таблице 1 , ясно указывают на существенное превышение показателей методологической грамотности аспирантов экспериментальных групп по сравнению с аспирантами контрольных групп, обучавшихся по методикам, не включающим обсуждаемый в статье логико-гносеологический контент педагогики.

Ещё одним диагностирующим умения выявлять корректность определения заданием было такое: проанализировать определение эвристического обучения, в котором оно раскрывается как форма обучения, предполагающая открытие и выработку самими учениками научных законов, формул, правил и истин. Ожидавшийся нами отклик обучающихся-участников эксперимента предполагал выявление того, что предложенное раскрытие эвристике не совсем соответствует: эвристика прежде всего акцентирует отмеченное автором определения субъективное открытие обучающимся истин внелогическим путём, близким к инсайту (озарению), конечно, являющимся итогом длительной мыслительной деятельности. Предложенная автором осмысливаемого определения расшифровка больше соответствует проблемно-креативному обучению. Неожиданным для нас оказалось то, что и в контрольных, и в экспериментальных группах результаты оказались низкими: приведённое выше возражение по поводу определения представили на начальном этапе лишь $3 \%$ респондентов в контрольных группах и 4 \% в экспериментальных группах; на финальном этапе результат выполнения близкого по 
смыслу задания в контрольных группах почти не изменился; а в экспериментальных группах увеличился также не слишком значительно лишь 25 \% респондентов дали желаемый организаторам эксперимента ответ. Тем не менее преимущества экспериментального обучения с углублённым методологическим контентом можно зафиксировать.

Диагностический контент включал и тесно связанные с заданиями на выявление корректности определений задания на выявления корректности классификаций, например, по критерию полноты разделения исследуемой совокупности и непересекаемости выделенных компонентов деления. В частности, мы предлагали магистрантам и аспирантам выявить корректность следующего утверждения: главной задачей педагогики является поиск способов развития жизненного опьта обучающуегося и источниками этого опьта являются вся объективная реальность (1), сам обучаюшиийся (2), педагог (3) и предшествуюший опьт обучающегося (4). Результат выполнения этого задания представлен в таблице 2 .

Таблииа 2

\section{Результат выполнения аспирантами диагностического задания на корректность определения и сопряжённой с ним классификации (метод поэлементного анализа). Общее число участников 98 человек, МГУТУ им. К. Г. Разумовского, 2017/18 уч. г.}

The result of the implementation by graduate students of a diagnostic assignment

for the correctness of the definition and the associated classification (element-by-element analysis method). The total number of participants 98 people, MSU K. G. Razumovsky

\begin{tabular}{|c|c|c|}
\hline $\begin{array}{l}\text { Элементы методологического знания, отображённые в отве- } \\
\text { тах участников эксперимента }\end{array}$ & $\begin{array}{l}\text { Число представив- } \\
\text { ших их аспирантов } \\
\text { контрольной } \\
\text { группы (в процен- } \\
\text { тах от общего } \\
\text { числа участников) }\end{array}$ & $\begin{array}{l}\text { Число представив- } \\
\text { ших их аспирантов } \\
\text { экспериментальной } \\
\text { группы (в процентах } \\
\text { от общего числа } \\
\text { участников) }\end{array}$ \\
\hline $\begin{array}{l}\text { 1. Поставили под сомнение заявленное автором основное со- } \\
\text { держание педагогики как развитие опыта обучающегося, не- } \\
\text { правомерно противопоставляемое им традиционному пред- } \\
\text { мету педагогики - «образовательный процесс», сопроводив это } \\
\text { подробным обоснованием }\end{array}$ & 7 & 45 \\
\hline $\begin{array}{l}\text { 2. Указали на неправомерность предложенного автором текста } \\
\text { разделения опыта обучающегося на четыре составляющих, до- } \\
\text { полнив это выявлением нарушения требований корректного } \\
\text { классифицирования }\end{array}$ & 9 & 67 \\
\hline $\begin{array}{l}\text { 3. Добавили ответ, представленный в п. 2, подробным обозна- } \\
\text { чением нарушения автором текста требований корректного } \\
\text { классифицирования, указав, что вся объективная реальность } \\
\text { включает двух её субъектов (ученик, учитель), а опыт ученика } \\
\text { включает приведённую автором текста его характеристику } \\
\text { (опыт, предшествующий обучению) - на этой основе выявлено } \\
\text { «четырежды некорректное» авторское классифицирование }\end{array}$ & 0 & 34 \\
\hline 4. Соединили в ответах содержание представленного в п. 1 и 2 & 0 & 38 \\
\hline
\end{tabular}


Вновь, как и в предыдущих случаях, существенное преимущество в трактовке обозначенного в стандартах научного образования методологического контента показывают аспиранты экспериментальной группы. Данный вывод подтверждается и анализом участия аспирантов в импровизированной учебной методологической дискуссии, первой частью которой являлось обсуждение участниками различий методики и методологии. Представители контрольной группы, участвовавшие в такой дискуссии, по большей части адресовались к методикам обучения и воспитания, применяющимся в практической педагогике, и хотя в этом случае различие методики и методологии очевидно, корректно обозначить его смогли только представители экспериментальной группы. Кроме того, участники дискуссии-представители экспериментальной группы как очевидное приняли адресацию слова «методика» исследовательскому сегменту деятельности участников педагогического поиска, правомерно соотнеся её с конкретной исследовательской программой, а также правомерно обозначив её отличия от методологии как учения о принципах, общенаучных регулятивах и технологиях исследовательской деятельности в педагогике.

Особым пунктом обсуждаемой сейчас учебной дискуссии стало дебатирование целесообразности подхода к определению педагогической методологии А. М. Новикова, включившего в неё методологию научно-исследовательской деятельности, методологию практической педагогической деятельности и методологию деятельности учебной. С этим исследовательским актом известного учёного практически согласились участники из контрольной группы, а участники из группы экспериментальной с некоторой помощью ведущего дискуссию педагога пришли к выводу о непродуктивности такой триады, в частности потому, что «методология» практической деятельности педагога и деятельности учебной неизбежно включает то, что традиционно относилось к самой педагогике, и компоненты традиционной методики практического педагогического плана получают методологические наименования. Однако такие переименования ни к чему новому не приводят, никакого теоретического и практического креатива не порождают, и потому бесполезны. Такой вывод, прозвучавший в результате совместного диалогового обсуждения сложных методологических сюжетов участниками экспериментальной учебной группы, мы считаем сильным аргументом в пользу нашей идеи о расширении методологического контента научного педагогического образования, элементы которого представлены в нашей статье выше.

Всё это позволяет нам в качестве результата исследования обозначить вывод о том, что способность исследователя эксцплицировать логико-гносеологическую атрибутику из читаемого научного текста положительно коррелирует с повышением уровня методологической грамотности. Это, в частности, означает, что оценка педагогом-исследователем степени достаточности $и$ корректности приводимых авторами читаемых текстов эмпирического и теоретического обоснований выводов (1), используемого анализа факторов, влияющих на протекание педагогических феноменов (2), проецирования читаемой информации в сущностный формат (3) опосредует: а) повышение уровня сформированности общенаучных умений корректной дефинитивности в отношении педагогических объектов и феноменов; б) повышение уровня сформированности умений корректного педагогического классифицирования; в) формирование умений соблюдения в исследовательских проектах базовых законов логики (достаточного основания, тождества, противоречия, исключённого третьего). 


\section{Заключение}

Методологическая грамотность педагога-исследователя в современных условиях, проявляющих сильную полифонию глоссария педагогики, адресуется главным образом формированию умения корректно дефинитивно отобразить объекты и феномены педагогической действительности. Это обусловливает необходимость овладения и постоянного совершенствования умений корректного сегментирования исследуемой педагогической совокупности, высвечиваемого с точки зрения полноты (максимально полной представленности в раскрывающей части определения всех признаков определяемого феномена), возможности постановки выявленных признаков в один смысловой ряд и непересекаемости содержательных полей, отображаемых языковым представлением этих признаков. На общенаучном языке это сопряжено с корректным соблюдением исследователем логических законов тождества и исключённого третьего.

К значимым сегментам методологической грамотности современного педагога-исследователя относится также умение логикосодержательного выстраивания цепочки выводов и умозаключений, аккомпанированного грамотным использованием логических законов противоречия и достаточного основания.

В статье показано, что овладение исследователем обозначенным контентом методологических умений причинно детерминируемо (на уровне одной из значимых причин): a) умением эксплицирования логико-гносеологической атрибутики из читаемых педагогических текстов, анализом того, насколько достаточны, логически и содержательно корректны и правильно адресуемы объектам научного рассмотрения приводимые авторами текстов эмпирические и теоретические обоснования; б) умением эксплицирования из читаемых текстов того, как их авторы осуществляют анализ влияющих на педагогические феномены факторов, как реализуют в своих текстовых продуктах сущностный формат рассмотрения проблем, выявляют распространённые заблуждения, мифологемы, некорректные умозаключения. Экспликация данной атрибутики из научных текстов логически и содержательно целесообразно продолжаема методологически выверенным научным диалогом читающего текст исследователя с автором читаемого текста.

\section{СПИСОК ЛИТЕРАТУРЫ}

1. Alexander P. A. Reflection and Reflexivity in Practice Versus in Theory: Challenges of Conceptualization, Complexity, and Competence // Educational Psychologist. - 2017. - Vol. 52, Issue 4. P. 307-314. DOI: https://doi.org/10.1080/00461520.2017.1350181

2. Barczyński B. J., Kalina R. M. Science of Martial Arts - Example of the Dilemma in Classifying New Interdisciplinary Sciences in the Global Systems of the Science Evaluation and the Social Consequences of Courageous Decisions // Procedia Manufacturing. - 2015. - Vol. 3. - P. 12031210. DOI: https://doi.org/10.1016/j.promfg.2015.07.199

3. Coney C. L. Critical Thinking in its Contexts and in Itself // Educational Philosophy and Theory. - 2015. - Vol. 47, Issue 5. - P. 515-528. DOI: https://doi.org/10.1080/00131857.2014.883963

4. Karpov A. O. The Problem of Separating the Notions of "Knowledge" and "Information" in the Knowledge Society and its Education // Procedia - Social and Behavioral Sciences. - 2017. Vol. 237. - P. 804-810. DOI: http://doi.org/10.1016/j.sbspro.2017.02.152 
5. Коржуев А. В., Антонова Н. Н. Логико-гносеологический формат педагогического познания и доказательная педагогика // Высшее образование в России. - 2018. - Т. 27, № 10. C. 136-145. DOI: https://doi.org/10.31992/0869-3617-2018-27-10-136-145 URL: https://elibrary.ru/item.asp?id=36319339

6. Садыкова А. Р., Никитина Э. К., Коржуев А. В., Икренникова Ю. Б. Курс История и философия науки" для педагогической аспирантуры (методологические размышления) // Высшее образование в России. - 2019. - Т. 28, № 2. - С. 79-93. URL: https://elibrary.ru/item.asp?id=37026034

7. Brezinka W. Philosophy of Educational Knowledge: An Introduction to the Foundations of Science of Education, Philosophy of Education and Practical Pedagogics. - Dordrecht: Springer, 1992. 303 p. DOI: https://doi.org/10.1007/978-94-011-2586-4

8. Lundie D. The Givenness of the Human Learning Experience and its Incompatibility with Informational Analytics // Educational Philosophy and Theory. - 2017. - Vol. 49, Issue 4. - P. 391404. DOI: https://doi.org/10.1080/00131857.2015.1052357

9. Alexander H. A. What is critical about critical pedagogy? Conflicting conceptions of criticism in the curriculum // Educational Philosophy and Theory. - 2018. - Vol. 50, Issue 10. - P. 903-916. DOI: https://doi.org/10.1080/00131857.2016.1228519

10. Pritchard D. Epistemic Virtue and the Epistemology of Education // Journal of Philosophy of Education. - 2013. - Vol. 47, Issue 2. - P. 236-247. DOI: https://doi.org/10.1111/14679752.12022

11. Shepperd J. Heidegger on Transforming the Circumspect Activity of Spatial Thought // Educational Philosophy and Theory. - 2016. - Vol. 48, Issue 8. - P. 752-763. DOI: https://doi.org/10.1080/00131857.2016.1165011

12. Leś T. The research potential of educational theory: On the specific characteristics of the issues of education // Educational Philosophy and Theory. - 2017. - Vol. 49, Issue 14. - P. 1428-1440. DOI: https://doi.org/10.1080/00131857.2017.1313716

13. Wettersten J. On the unification of psychology, methodology, and pedagogy: Selz, Popper, and Agassi // Interchange. - 1987. - Vol. 18, Issue 4. - P. 1-14. DOI: https://doi.org/10.1007/BF01812234

14. Kornienko A. A. The Concept of Knowledge Society in the Ontology of Modern Society // Procedia - Social and Behavioral Sciences. - 2015. - Vol. 166. - P. 378-386. DOI: https://doi.org/10.1016/j.sbspro.2014.12.540

15. Mallaband B., Wood G., Buchanan K., Staddon S., Mogles N. M., Gabe-Thomas E. The reality of cross-disciplinary energy research in the United Kingdom: A social science perspective // Energy Research and Social Science. - 2017. - Vol. 25. - P. 9-18. DOI: http://doi.org/10.1016/j.erss.2016.11.001

16. Koskinen H. J. Antecedent Recognition: Some Problematic Educational Implications of the Very Notion // Journal of Philosophy of Education. - 2018. - Vol. 52, Issue 1. - P. 178-190. DOI: https://doi.org/10.1111/1467-9752.12276

17. Сапунов М. Б. О проблеме реальности в истории и философии науки // Высшее образование в России. - 2012. - № 2. - C. 147-155. URL: https://elibrary.ru/item.asp?id=17357739

18. Зуев В. В. На пути к теории биологической таксономии // Философия науки и техники. 2016. - T. 21, № 1. - C. 36-54. URL: https://elibrary.ru/item.asp?id=26189732

19. Коржуев А. В., Соколова А. С. Методы выявления незавершенных актуальных фрагментов педагогического знания // Интеграция образования. - 2017. - Т. 21, № 3 (88). - С. 535-545. URL: https://elibrary.ru/item.asp?id=30031198 
20. Korzhuev A. V., Madzhuga A. G., Kislyakov P. A., Amirov A. F., Sokolova A. S., Ikrennikova Y. B. Semantic Content of Pedagogic Knowledge and the Problem of Comprehension // Ponte. - 2017. - T. 73, № 10. - P. 274-280. URL: https://elibrary.ru/item.asp?id=31065205

21. Snaza N. Aleatory entanglements: (Post)humanism, hospitality, and attunement - A response to Hugo Letiche // Journal of Curriculum and Pedagogy. - 2017. - Vol. 14, Issue 3. - P. 256-272. DOI: https://doi.org/10.1080/15505170.2017.1398700

22. Letiche H. Bewildering pedagogy // Journal of Curriculum and Pedagogy. - 2017. - Vol. 14, Issue 3. - P. 236-255. DOI: https://doi.org/10.1080/15505170.2017.1335662 
DOI: $10.15293 / 2658-6762.1903 .05$

Albina Rifovna Sadikova,

Doctor of Pedagogical Sciences, Professor,

Department of Informatics and Applied Mathematics, Institute of Digital

Education,

Moscow City Pedagogical University, Moscow, Russian Federation.

ORCID ID: https://orcid.org/0000-0002-1413-200X

E-mail: albsad2008@yandex.ru

Irina Vitalievna Levchenko,

Doctor of Pedagogical Sciences, Professor,

Department of Informatics and Applied Mathematics of the Institute of

Digital Education,

Moscow City Pedagogical University, Moscow, Russian Federation.

ORCID ID: https://orcid.org/0000-0002-1388-4269

E-mail: ira-lev@yandex.ru

Natalia Alexandrovna Usova,

Candidate of Pedagogical Sciences, Docent,

Department of Informatics and Applied Mathematics of the Institute of

Digital Education,

Moscow City Pedagogical University, Moscow, Russian Federation.

ORCID ID: https://orcid.org/0000-0002-1728-7736

E-mail: usova-n@mail.ru

Yulia Borisovna Ikrennikova,

Candidate of Pedagogical Sciences, Docent,

Department of Pedagogy and Psychology of Professional Education,

K. G. Razumovsky Moscow State University of Technologies and Management, Moscow, Russian Federation.

ORCID ID: https://orcid.org/0000-0002-2141-6289

E-mail: ikren@yandex.ru

Andrey Vyacheslavovich Korzhuev,

Doctor of Pedagogical Sciences, Professor,

Department of Medical and Biological Physics,

I. M. Sechenov First Moscow State Medical University, Moscow, Russian

Federation.

ORCID ID: https://orcid.org/0000-0002-7454-038X

E-mail: akorjuev@mail.ru

Elena Leont'evna Ryazanova,

Candidate of Pedagogical Sciences, Associate Professor,

Department of Medical and Biological Physics,

I. M. Sechenov First Moscow State Medical University, Moscow, Russian

Federation.

ORCID ID: https://orcid.org/0000-0002-1375-3373

E-mail: scarobey64@mail.ru 


\title{
Explication of logical-gnoseological content of academic texts as a factor affecting the methodological competence of educational researchers
}

\begin{abstract}
Introduction. The authors investigate logical-gnoseological content of pedagogical knowledge and methods of its identification. The purpose of the article is to reveal how the ability to explicate logical-gnoseological content of academic texts affects methodological competence of educational researchers.

Materials and Methods. The research involved the set of following methods: (a) the analysis of scientific literature, with the main focus on pedagogical knowledge and methods of educational research in order to identify the field of pedagogical theory which needs further investigation; (b) statement of a hypothesis about the influence of researchers' ability to explicate logical-gnoseological content of the text on the level of their methodological competence; c) theoretical causal analysis of the increase in the level of methodological competence of researchers; (d) the local educational experiment to confirm the hypothesis.

Results. It is found that the activity of educational researchers involving revealing and logicalsubstantial developing empirical conclusions, theoretical justifications, comparisons, the intrinsic analysis of phenomenological manifestations, results of the analysis of the factors which influence the studied process, contained in academic texts, promotes increase in level of methodological competence of educational researchers. It is expressed in the ability to define and to classify the theoretical field of education, to follow the laws of sufficient reasoning, identity, non-contradiction and the law of the excluded middle in making conclusions.

Conclusions. The methodological competence of educational researchers is determined (as one of the significant reasons) by the ability to explicate the following logical-gnoseological content of the analyzed academic text: a) identifying sufficiency, substantial and logical correctness, the correct addressability of theoretical and empirical justification to the considered phenomena; $b$ ) the correct analysis of the factors influencing on educational phenomena; $c$ ) displaying research consideration in an intrinsic format.
\end{abstract}

\section{Keywords}

Logical-epistemological content of pedagogy; Explication meanings in a text; Empirical justification; Theoretical justification; Contextual justification; Logical refutation; Correct pedagogical analytics.

\section{Acknowledgements}

The reported study was supported by Russian Ministry of Education and Science under 5-100 Excellence Programme.

\section{REFERENCES}

1. Alexander P. A. Reflection and reflexivity in practice versus in theory: Challenges of conceptualization, complexity, and competence. Educational Psychologist, 2017, vol. 52, issue 4, pp. 307-314. DOI: https://doi.org/10.1080/00461520.2017.1350181

2. Barczyński B. J., Kalina R. M. Science of martial arts - example of the dilemma in classifying new interdisciplinary sciences in the global systems of the science evaluation and the social consequences of courageous decisions. Procedia Manufacturing, 2015, vol. 3, pp. 1203-1210. DOI: https://doi.org/10.1016/j.promfg.2015.07.199

3. Coney C. L. Critical thinking in its contexts and in itself. Educational Philosophy and Theory, 2015, vol. 47, issue 5, pp. 515-528. DOI: https://doi.org/10.1080/00131857.2014.883963 
4. Karpov A. O. The problem of separating the notions of "knowledge" and "information" in the knowledge society and its education. Procedia - Social and Behavioral Sciences, 2017, vol. 237, pp. 804-810. DOI: http://doi.org/10.1016/j.sbspro.2017.02.152

5. Korzhuev A. V., Antonova N. N. Epistemological format of pedagogical science and evidencebased pedagogy. Higher Education in Russia, 2018, vol. 27, no. 10, pp. 136-145. (In Russian) DOI: https://doi.org/10.31992/0869-3617-2018-27-10-136-145 URL: https://elibrary.ru/item.asp?id=36319339

6. Sadyikova A. R., Nikitina E. K., Korzhuev A. V., Ikrennikova Y. B. Course "History \& philosophy of science" for doctoral programs in education and pedagogical sciences. Higher Education in Russia, 2019, vol. 28, no. 2, pp. 79-93. (In Russian) URL: https://elibrary.ru/item.asp?id=37026034

7. Brezinka W. Philosophy of Educational Knowledge: An Introduction to the Foundations of Science of Education, Philosophy of Education and Practical Pedagogics. Dordrecht, Springer Publ., 1992, 303 p. DOI: https://doi.org/10.1007/978-94-011-2586-4

8. Lundie D. The givenness of the human learning experience and its incompatibility with informational analytics. Educational Philosophy and Theory, 2017, vol. 49, issue 4, pp. 391404. DOI: https://doi.org/10.1080/00131857.2015.1052357

9. Alexander H. A. What is critical about critical pedagogy? Conflicting conceptions of criticism in the curriculum. Educational Philosophy and Theory, 2018, vol. 50, issue 10, pp. 903-916. DOI: https://doi.org/10.1080/00131857.2016.1228519

10. Pritchard D. Epistemic virtue and the epistemology of education. Journal of Philosophy of Education, 2013, vol. 47, issue 2, pp. 236-247. DOI: https://doi.org/10.1111/1467-9752.12022

11. Shepperd J. Heidegger on transforming the circumspect activity of spatial thought. Educational Philosophy and Theory, 2016, vol. 48, issue 8, pp. 752-763. DOI: https://doi.org/10.1080/00131857.2016.1165011

12. Leś T. The research potential of educational theory: On the specific characteristics of the issues of education. Educational Philosophy and Theory, 2017, vol. 49, issue 14, pp. 1428-1440. DOI: https://doi.org/10.1080/00131857.2017.1313716

13. Wettersten J. On the unification of psychology, methodology, and pedagogy: Selz, Popper, and Agassi. Interchange, 1987, vol. 18, issue 4, pp. 1-14. DOI: https://doi.org/10.1007/BF01812234

14. Kornienko A. A. The concept of knowledge society in the ontology of modern society. Procedia - Social and Behavioral Sciences, 2015, vol. 166, pp. 378-386. DOI: https://doi.org/10.1016/j.sbspro.2014.12.540

15. Mallaband B., Wood G., Buchanan K., Staddon S., Mogles N. M., Gabe-Thomas E. The reality of cross-disciplinary energy research in the United Kingdom: A social science perspective. Energy Research and Social Science, 2017, vol. 25, pp. 9-18. DOI: http://doi.org/10.1016/j.erss.2016.11.001

16. Koskinen H. J. antecedent recognition: Some problematic educational implications of the very notion. Journal of Philosophy of Education, 2018, vol. 52, issue 1, pp. 178-190. DOI: https://doi.org/10.1111/1467-9752.12276

17. Sapunov M. B. To the problem of reality in history and philosophy of science. Higher Education in Russia, 2012, no. 2, pp. 147-155. (In Russian) URL: https://elibrary.ru/item.asp?id=17357739

18. Zuev V. V. On the way to the theory of biological taxonomy. Philosophy of Science and Technology, 2016, vol. 21, no. 1, pp. 36-54. (In Russian) URL: https://elibrary.ru/item.asp?id=26189732 
19. Korzhuyev A. V., Sokolova A. S. Methods for revealing incomplete topical fragments of pedagogical knowledge. Integration of Education, 2017, vol. 21, no. 3 (88), pp. 535-545. (In Russian) URL: https://elibrary.ru/item.asp?id=30031198

20. Korzhuev A. V., Madzhuga A. G., Kislyakov P. A., Amirov A. F., Sokolova A. S., Ikrennikova Y. B. Semantic content of pedagogic knowledge and the problem of comprehension. Ponte, 2017, vol. 73, no. 10, pp. 274-280. URL: https://elibrary.ru/item.asp?id=31065205

21. Snaza N. Aleatory entanglements: (Post)humanism, hospitality, and attunement - A response to Hugo letiche. Journal of Curriculum and Pedagogy, 2017, vol. 14, issue 3, pp. 256-272. DOI: https://doi.org/10.1080/15505170.2017.1398700

22. Letiche H. Bewildering pedagogy. Journal of Curriculum and Pedagogy, 2017, vol. 14, issue 3, pp. 236-255. DOI: https://doi.org/10.1080/15505170.2017.1335662

Submitted: 30 March 2019 Accepted: 06 May 2019 Published: 30 June 2019

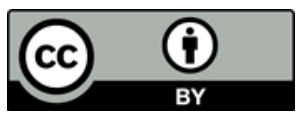

This is an open access article distributed under the Creative Commons Attribution License which permits unrestricted use, distribution, and reproduction in any medium, provided the original work is properly cited. (CC BY 4.0). 